\title{
Fabrication of Titanium Coatings for Medical Device Applications
}

$$
\text { Hong } \mathrm{ZHOU}^{1, \mathrm{a}^{*}} \text { and Cheng PENG }{ }^{2, \mathrm{~b}}
$$

\author{
${ }^{1}$ Centre for Engineering and Industrial Design, Waikato Institute of Technology, Hamilton 3240, \\ New Zealand
}

\author{
${ }^{2}$ Technical Centre, GAC Motor Co., Ltd, Guangzhou 511434, P. R. China \\ ahong.zhou@wintec.ac.nz, bPengch@gacmotor.com
}

\section{Keywords: Titanium coatings, Medical device applications, Shroud, Plasma spray; Microstructure}

\begin{abstract}
Titanium is widely used for medical purposes. It related to bone repair because of its favorable mechanical properties and biocompatible ability to osseointegrate in host bone tissue. A good and lasting connection of the implant with the bone tissue is possible when there are sufficient conditions for the bone to grow into the pores of the material, therefore the use of a porous titanium coating may be helpful in solving this problem. In this paper, shrouded plasma spray is used to produce low oxide containing titanium coatings and lower the cost as titanium is a very reactive metal at high temperatures. A solid conical shroud was designed for plasma spray. The titanium coatings were assessed by scanning electron microscopy and energy dispersive X-ray spectroscopy. An analysis in microstructure had been carried out. The results showed that the shroud attachment played an important role in protecting the titanium particles in flight during the process of plasma spraying. An enhanced microstructure with moderate porosity in the titanium coatings plasma sprayed with the shroud was observed. The reduction in air entrainment with the shroud resulted in a good heating of the particles. The plasma-sprayed titanium coating was mainly composed of $\alpha$-Ti with a low quantity of $\mathrm{TiO}$.
\end{abstract}

\section{Introduction}

Titanium is an ideal biomedical metallic material for implant because of the outstanding specific strength and good compatibility with the human body. Meanwhile, titanium has a good resistance to corrosion environment in the human body, and is reconcilable with living tissue and bone of the body [1-3]. Titanium alloys are also often used thanks to their excellent strength, fracture toughness, and great corrosion resistance, which play a pivotal role for the material selection of orthopedic devices [3]. Ti-6Al-4V alloy is normally employed in the most biomedical applications. However, the presence of toxic $\mathrm{Al}$ and $\mathrm{V}$ in this titanium alloy has impaired its biocompatibility and limited the further application [3-4]. The electrochemical properties of titanium are far better than other metals since titanium can form immediately a thin film of passive titanium oxide, $\mathrm{TiO}_{2}$, on the outer surface when it is exposed with a certain amount of oxygen [2-4]. Pure titanium is appropriate for the carrier structure for replacement heart valves and heart pacemaker cases. Titanium and its alloys have a relatively low elastic modulus, which can mitigate the difference of stiffness between the implant and the bone in human's body [5-6]. This is a key factor to the traditional application of titanium and its alloys as knee joints and hip implants, but also to bone fracture screws and plates [5-6]. As we know, a well-compatible and lasting connection between the bone tissue and the implant becomes feasible when sufficient conditions for the bone to grow into the pores of the material can be reached. Therefore, the utilization of a porous implant with titanium coatings might be beneficial in solving this problem [7-8].

Plasma spray technology can combine a thin coating of high value material onto structural materials. In the plasma spray process, the plasma with high heat energy is used to accelerate and melt fine feedstock particles onto a prepared substrate. These molten particles normally cool down in a very short time upon impact, and then solidify to form splats instantly by heat transfer. By accumulation, a coating consisting of lamellae is built up [9-10]. Plasma spray process has been used for several decades to deposit various coatings for different purposes such as thermal barrier, wear 
resistance and biocompatibility so on. Shrouded plasma spray modifies the spray torches by using a shroud attachment at the end of plasma gun [11-12]. The shroud could shield the plasma flame physically from the ambient air. So, it isolates the molten feedstock particles at high temperatures during the flight in the plasma jet from reaction with oxygen and nitrogen in the air.

In this study, an investigation on shrouded plasma spray to fabricate titanium coatings were conducted. A shroud attachment was used to produce titanium coatings with low oxide containing and to lower the cost because pure titanium at high temperatures is very reactive. An analysis on microstructure and phase composition of titanium coatings had been carried out.

\section{Materials and Experimental}

Materials. The gas atomized (GA) pure titanium powder from Xi'an Lilin International Trade Co., Ltd., Xi'an, China was commercialy availble, and used as feedstock powder for titanium coatings. The GA titanium powder has a range of particle size from $45 \mu \mathrm{m}$ to $75 \mu \mathrm{m}$. The titanium particle morphology is shown in figure 1, and table 1 gives the chemical composition of the GA titanium powder provided by the supplier.

Table 1. Chemical composition of the pure titanium powder

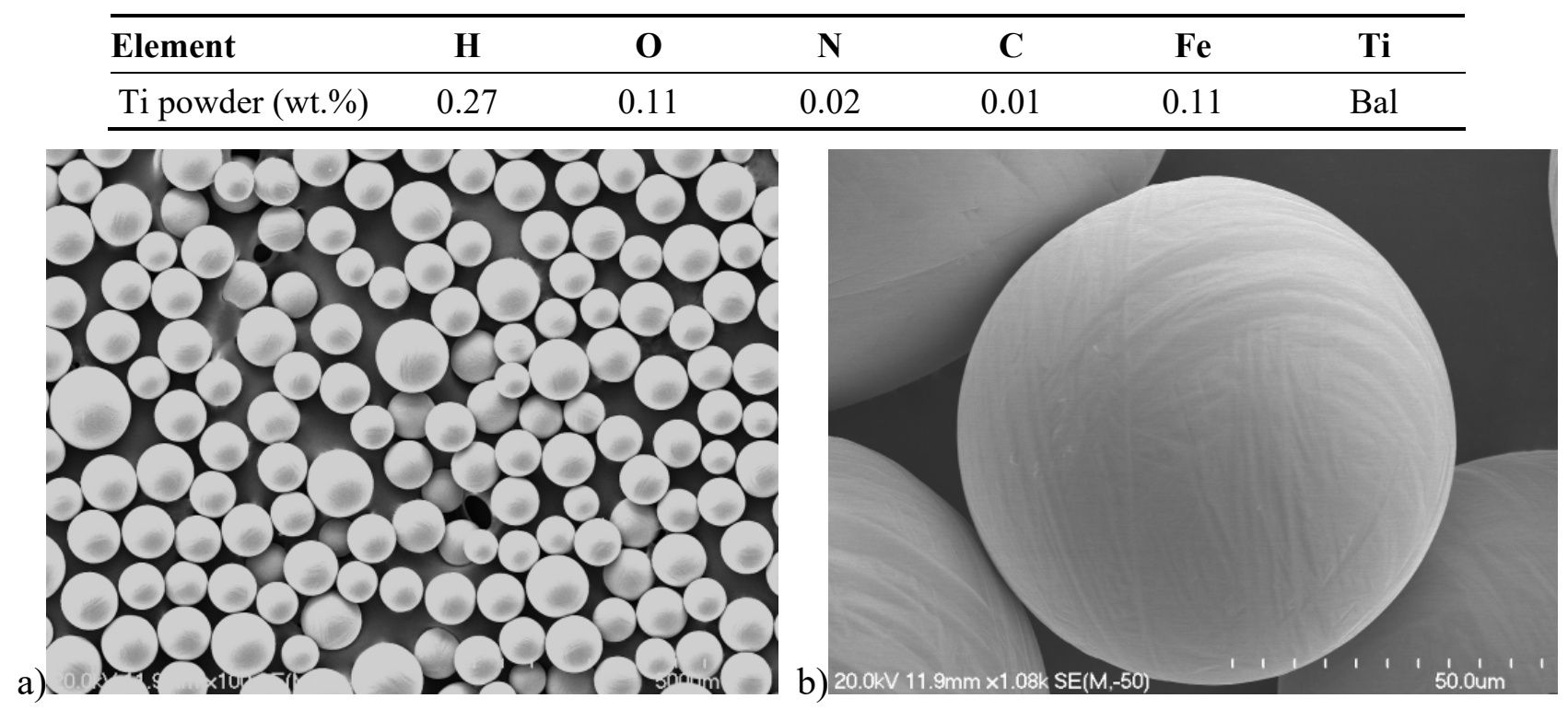

Figure 1. The SEM particle morphology of the GA titanium powders at different magnifications a) low magnification; b) high magnification

Method. Mild steel was used as the substrates with dimensions of $100 \times 25$ × $3 \mathrm{~mm}$. The GA pure titanium powder was deposited onto the mild steel substrates by the SG-100 plasma gun (Praxair surface technologies, USA) which was mounted on a 6-axis robot. The plasma spray parameters are presented in table 2 . A shroud attachment has been used for the plasma spray process, as shown in figure $2[12]$.

Table 2. The parameters for the plasma sprayed titanium coatings

\begin{tabular}{cc}
\hline Spraying Parameters & Setting \\
\hline Voltage, $\mathrm{V}$ & 80 \\
Current, A & 800 \\
Argon, Primary gas, slpm & 85 \\
Helium, Auxiliary gas, slpm & 18 \\
Powder feed rate, g/min & 30 \\
Spray distance, $\mathrm{mm}$ & 100 \\
Transverse speed, $\mathrm{m} / \mathrm{s}$ & 0.5 \\
\hline
\end{tabular}



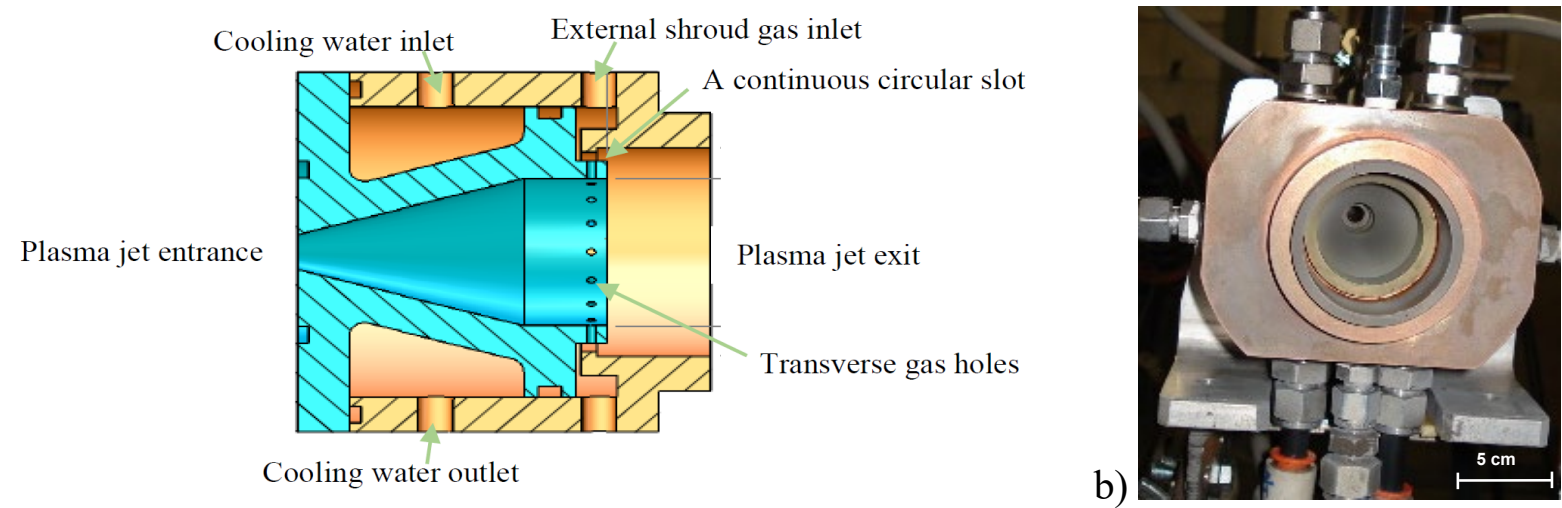

Figure 2. The shroud attachment for plasma sprayed titanium coatings.

a) schematic cross section of the shroud; b) the experimental setup of the shrouded plasma spraying

Microstructural Characterization. Cross sectional specimens of the as-sprayed titanium coatings were used for microstructural analysis after metallographical preparason. The microstructures and morphologies of the as-sprayed titanium coatings were observed and assessed by using scanning electron microscope (SEM, Hitachi S4700, Japan). The chemical compositions and element distribution on a microscopic scale were detected and analyzed by using an energy dispersive X-ray spectroscopy (EDS, Oxford INCA, UK), which was attached to the scanning electron microscop. Phase informations were inspected by using a X-ray diffractometer (XRD, Bruker, model D8, Germany) with CuK $\alpha$ radiation at $40 \mathrm{kV}$ and $30 \mathrm{~mA}$; the scanning speed of $2 \theta$ was $2^{\circ} \mathrm{min}^{-1}$ and the measuring angle was from $25^{\circ}-80^{\circ}$.

\section{Results and Discussions}

Microstructural Analyses. Figure 3 depicts the polished cross section morphologies of the shrouded titanium coatings at different magnifications. The SEM images reveal that the titanium coatings plasma sprayed with the shroud had a dense microstructure with a moderate porosity. In principle a good heating of the titanium particles during the process of shroud plasma spraying was expected to be set up because the reduction of air entrainment with the shroud. Thus, more titanium particles in the fully-molten state at higher temperatures during the flight in the plasma flame could be obtained, which helped to attain the dense microstructure with moderate porosity in the as-sprayed titanium coatings. This results indicated that the shroud attachemnt in the plasma spraying played a key part in protecting the titanium particles from the in-flight oxidation during the process of plasma spraying. In figure $3 \mathrm{~b}$, the un-melted particle was also observed with some voids around. Usually, GA titanium powders with solid sphere is a little relatively difficult to melt in the plasma spraying because of less surface area for heat transfer.

a)
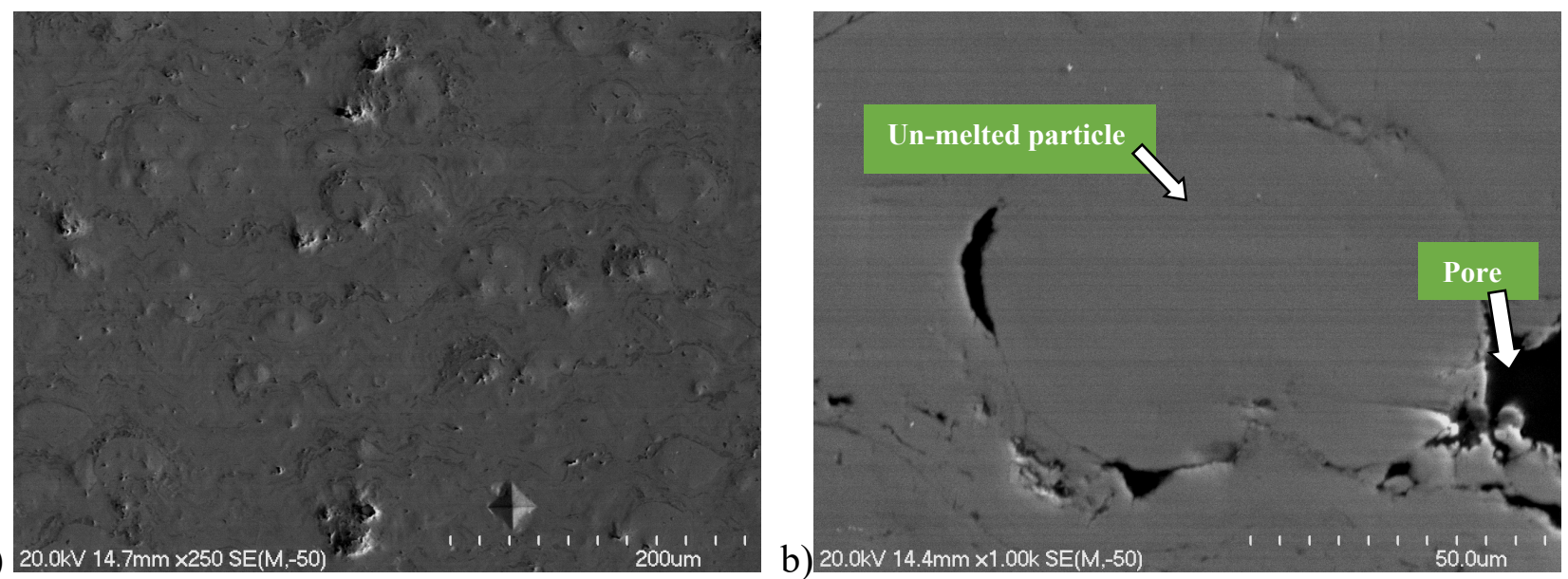

Figure 3. SEM images of cross section of shrouded titanium coatings at different magnification a) low magnification; b) high magnification 
The SEM morphologies and element linear distribution of the shrouded plasma-sprayed titanium coatings are shown in figure 4 . The element distribution of the titanium coating was determined by EDS. Figure $4 \mathrm{~b}$ illustrates the variation of $\mathrm{Ti}$ and $\mathrm{O}$ contents along the given line on the surface of the titanium coatings. The EDS analyses indicated that the top surface of the shrouded titanium coating presented a chemical composition close to pure titanium. The decrease of titanium content in the middle way is due to the presence of a void. The oxygen content remained at a very low level along all the way. This result verifies that the shrouding system in the plasma spray process took a useful effect of physical shielding to prevent the oxidation from ambient air.

a)
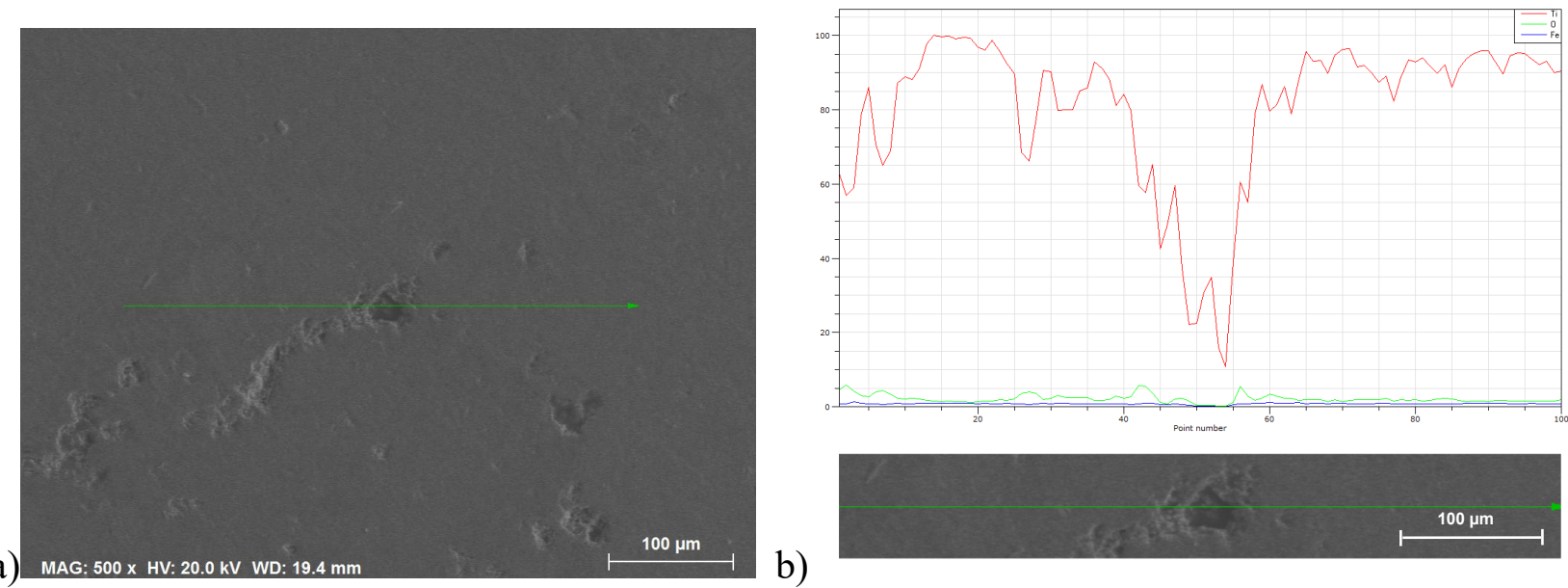

b)

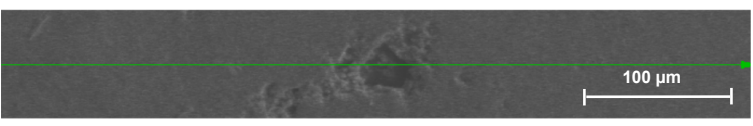

Figure 4. The SEM image (a) and element linear distribution of Ti coating (b)

Phase composition. The XRD patterns of the GA titanium power and the as-sprayed titanium coatings with the shroud are illustrated in figure 5. It is noticed from the XRD peaks in figure 5a that the GA titanium powder is completely constituted by the $\alpha$-Ti phase. Titanium oxide was not observed in the GA titanium powder. On the other hand, the as-sprayed titanium coating with the shroud presents an XRD pattern which is quite like the pure titanium powder's curve, as shown in figure $5 \mathrm{~b}$. The result implies that the leading phase in the as-sprayed titanium coating with the shroud is still the $\alpha$-Ti. Meanwhile, we also observed that all the peaks in the as-sprayed titanium coating's XRD pattern were apparently expanded. The broadening widths of the peaks in the as-sprayed titanium coating's pattern suggests that a microstructure with finer grains in the shrouded plasma-sprayed titanium coating was obtained. Meanwhile, a relative weak peak for oxide of titanium, TiO, could also be seen in the as-sprayed titanium coating's XRD pattern, so a small quantity of monoxide of titanium in the shrouded plasma-sprayed titanium coatings might probably exist. The quantity of titanium monoxide in the shrouded titanium coating would stay at a very low level as a matter of fact that the intensity of titanium oxide peak in the XRD result was very weak, plus that only one peak of the titanium monoxide was found in the XRD pattern. As we know, $\mathrm{TiO}_{2}$ is normally the existing form in nature rather than in the form of TiO, since the monoxide of titanium can readily be oxidized to bring into being of the dioxide of titanium when exposed with reasonable amounts of oxygen. For the as-sprayed titanium coatings with the shroud in this study, the oxide is only composed of TiO. This can be explained that the titanium particles have a very short staying time in the plasma flame during the plasma spraying process since they were significantly accelerated by plasma jet. Next, a very fast cooling rate (in the $10^{6}-10^{9} \mathrm{Ks}^{-1}$ range) was then achieved due to a rapid heat transfer when the titanium particles impacting upon the mild steel substrates [9-10]. Therefore, this resulted in the quick formation of titanium monoxide rather than dioxide of titanium in the plasma-sprayed titanium coatings with the shroud. 

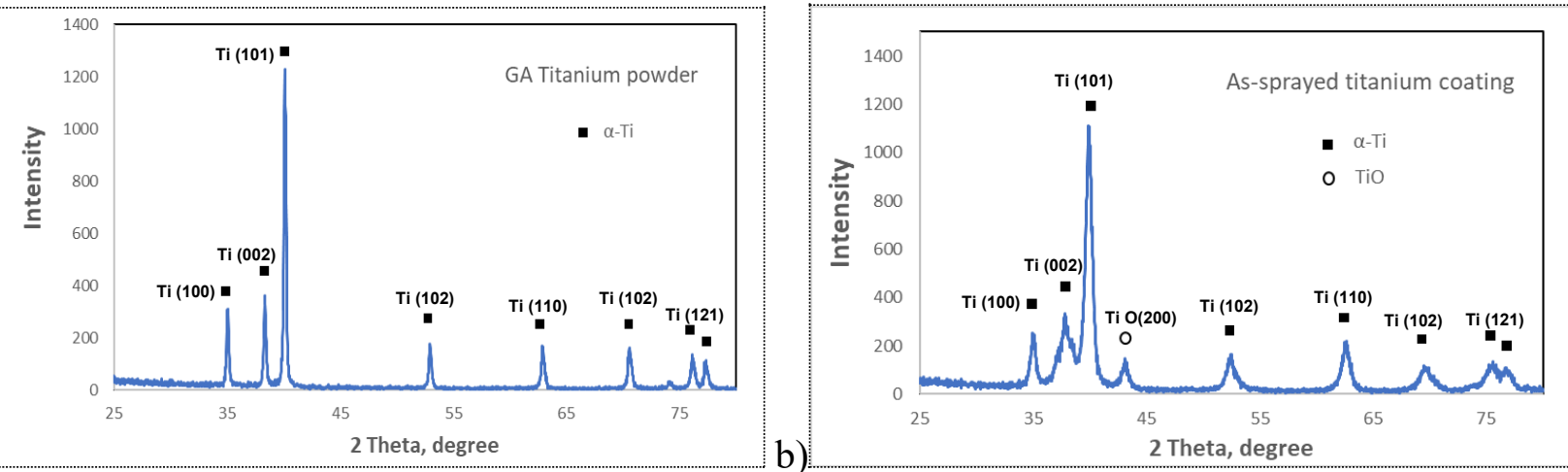

a)

b)

2 Theta, degree

Figure 5. XRD patterns in the range of $2 \theta=25-80^{\circ}$ of a) the titanium powder and $b$ ) the titanium coating

\section{Conclusions}

Titanium is widely used for medical purposes because of its favorable mechanical properties and biocompatible ability. The connection of the bone tissue with the implant becomes important. The moderate pores at the surface of implant will enhance the bone tissue to grow. Therefore, the utilization of a porous titanium coating may be helpful in solving this problem. This work presents the feasibility of using the shrouded plasma spraying to fabricate titanium coatings with moderate porosity. Microstructural characterization was carried out for the titanium coatings. The presence of the shroud resulted in a better heating of in-flight titanium particles and led to a moderate level of porosity. The shrouded titanium coating had an enhanced microstructure; the dominant phase in the titanium coatings plasma-sprayed with the shroud were $\alpha$-Ti. A low quantity of TiO was also found in the titanium coatings.

\section{References}

[1] C. Elias, J. Lima, R, Valiev, Biomedical applications of titanium and its alloys, JOM 60(2008) 46-49.

[2] C. Leyens, M. Peters, Titanium and titanium alloys, Weinheim, Germany, 2003.

[3] L. Zhang, L. Chen, A Review on Biomedical Titanium Alloys: Recent Progress and Prospect, Adv. Eng. Mater. 21(2019) 1801215.

[4] L. Chen, Y. Cui, L. Zhang, Recent Development in Beta Titanium Alloys for Biomedical Applications, Metals 10(2020) 1139.

[5] A. Agnes, K. Saravana, S. Eko, Surface modification of titanium and its alloys for the enhancement of osseointegration in orthopaedics. Current Science 111(2016) 1003-1015.

[6] H. Shahali, A. Jaggessar, P. Yarlagadda, Recent advances in manufacturing and surface modification of titanium orthopaedic applications. Procedia Engineering 174(2017)1067-1076.

[7] M. Kulkarni, A. Mazare, E. Gongadze, Titanium nanostructures for biomedical applications, Nano- technology 26(2015) 062002.

[8] S. Wu, X. Liu, K. Yeung, Biomimetic porous scaffolds for bone tissue engineering. Materials Science and Engineering: R: Reports 80(2014) 1-36.

[9] P. Fauchais, G. Montavon, G. Bertrand, From powders to thermally sprayed coatings. J. Therm. Spray Technol. 19(2010) 56-80.

[10] P. Fauchais, M. Vardelle, S. Goutier, Latest researches advance of plasma spraying: From splat to coating formation. J. Therm. Spray Technol. 25(2016) 1534-1553.

[11] H. Zhou, Z. Liu, L. Luo, Microstructural characterization of shrouded plasma sprayed titanium coatings. J. Manuf. Mater. Process. 3(2019) jmmp3010004.

[12] H. Zhou, C. Peng, Effect of shroud in plasma spraying on chemical composition and thickness of titanium coatings, Coatings, 11(2021) 446. 